\title{
Assessment of dynamic vulnerability by TCR method: Application to the aquifer R'Mel (Morocco)
}

\author{
Hind Es saouini ${ }^{1}$, Mina Amharref ${ }^{2}$ and Abdes Samed Bernoussi ${ }^{3}$ \\ ${ }^{1,2}$ and 3 (Department of Earth Sciences, Geoinformation and Land Management Team (GAT)/ Faculty of Science \\ and Technology, Morocco)
}

\begin{abstract}
In the aim to test the temporal vulnerability variability, assessed by TCR method, we have considered in this work data on R'Mel aquifer for two different hydrological years. The TCR is an indexing and weighting method, taking into account three parameters characterizing the transfer of a contaminant from the Soil Interface Zone (SIZ) to the water table: the transit time (T) of a pollutant through the Unsaturated Zone (UZ), the purification degree $\left(C^{\prime} p / C p\right)$ and the recharge degree $\left(R^{\prime} / R\right)$. Assessment and vulnerability mapping of the $R^{\prime} M e l$ aquifer for the years 2003 and 2005 considered as wet and dry respectively, allowed us to get two maps. These vulnerability maps are slightly different, while the maps of the three parameters have significant variations. Indeed, the range vulnerability index obtained is between 0.14 and 7.9 for 2003 and between 0.067 and 8.5 for 2005. This index variation is reflected on $8 \%$ of the total area of the study zone. However, the weights of the three parameters determined by the sensitivity tests are the same.
\end{abstract}

Keywords: Dynamic Vulnerability; TCR; susceptibility tests; R'Mel (Morocco)

\section{Introduction}

The term vulnerability has been used by Margat since the late $60 \mathrm{~s}$ to characterize the degree of natural protection that reduces or even prevents the infiltration of pollutants into groundwater. Thus, the concept of groundwater vulnerability is based on the assumption that the physical environment can provide a degree of natural protection against potential pollution. This concept takes into account some various physical factors determining the sensitivity of these aquifers dealing with pollution from the soil interface zone [1]. Indeed, the vulnerability mapping of aquifers is used to identify the area most exposed to potential contamination and where protective measures are necessary [2].Currently, in order to better protect water resources, the vulnerability maps are used as a tool for decision support in the planning of land use. But given the complexity of the mechanisms governing the transfer of a pollutant, the multitude and variety of the factors taken into account, several approaches have been proposed for the assessment of vulnerability. These approaches differ from one author to another, depending on the design, the number of parameters used and the nature of the aquifer. Therefore, for a given area, the selection of the most appropriate method is not always easy. In this work, we assess the vulnerability of the R'Mel groundwater in Morocco for two different rainfall years, by the application of the TCR method. This approach, introduced by Amharref et al [3], [4] and [5], consists in determining the vulnerability index Iv which depends on three parameters involved in the transfer of the pollutant. These are: the transit time $(\mathrm{T})$ of a pollutant through the unsaturated zone, the purification degree $\left(\mathrm{C}^{\prime} \mathrm{p} / \mathrm{Cp}\right)$ and the recharge degree $\left(R^{\prime} / R\right)$. This index is given by the weighted sum of these three parameters [6]. The application of the TCR method to the same study area for two different rainfall years will allow us to see if the vulnerability is dynamic and to infer the causes of its variability.

\section{Methodology}

To study the temporal variation of vulnerability we consider two different pluviometric years. As an application we consider the R'Mel aquifer (Morocco) known by a high spatial and temporal variability of rainfall. Indeed, the elaboration of two vulnerability maps by the same method for two different years requires the use of measured data in the same points. The points will also serve to determinate the weights of parameters $\mathrm{T}, \mathrm{C} / \mathrm{p} / \mathrm{Cp}$ and $\mathrm{R} ' \mathrm{R}$. These weights are determined by sensitivity tests to be carried out on the same control wells which represent important variations of the three parameters. Data were collected from the various departments and agencies in charge of the sectors of water, agriculture and meteorology (Loukkos Water Basin Agency, Loukkos Regional Office of Agricultural Development...). The choice of rainfall in 2003 and 2005 years was imposed by the availability of data that fulfill all these conditions.

\subsection{Presentation of the TCR method}

The TCR method is based on a quantitative assessment of transfer mechanisms of a pollutant based on a multi-conceptualization of the traversed medium [3], [4] and [5]. The vulnerability index Iv is evaluated as a weighted sum of the effect of the three parameters characterizing the transfer of a contaminant from the soil 
interface zone to the aquifer (fig. 1). The transit time, T, through the coverage area, the purification degree $C^{\prime} p / C p$ (the ratio of the pollutant concentration, $C$ 'p, reaching the water table and the initial pollutant concentration in the aquifer, $\mathrm{Cp}$ ) and the recharge degree $\mathrm{R}^{\prime} / \mathrm{R}$ (ratio of the effective recharge, $\mathrm{R}^{\prime}$, relative to the potential recharge, $\mathrm{R})$.

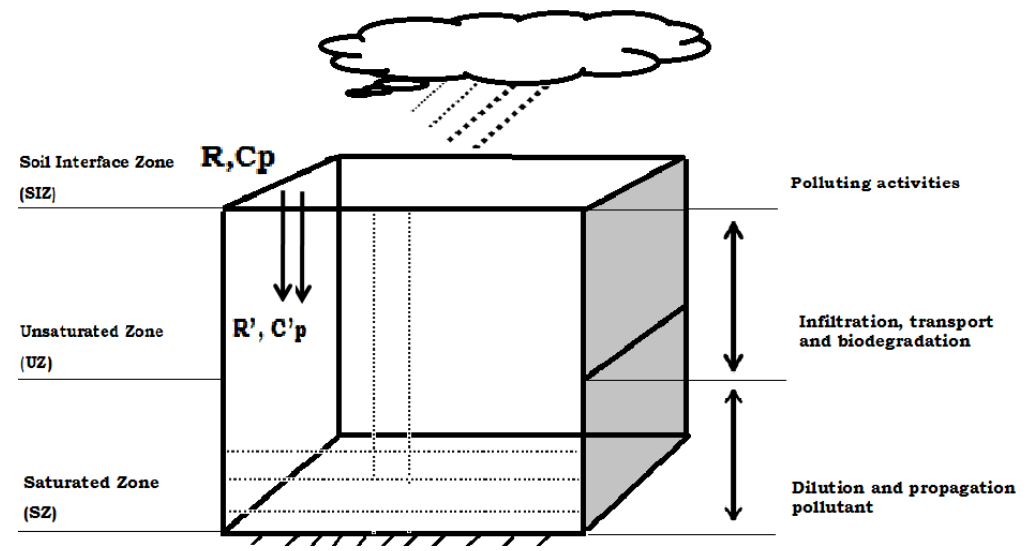

Figure 1: Diagram of groundwater contamination

The vulnerability index is given by the following relation (1):

$$
\mathrm{Iv}=\alpha \frac{1}{\mathrm{~T}}+\beta \frac{\mathrm{Cp}^{\prime}}{\mathrm{Cp}}+\gamma \frac{\mathrm{R}^{\prime}}{\mathrm{R}}
$$

$\alpha, \beta$ and $\gamma$ are positive weight coefficients and their determination is done by sensitivity tests on control wells in the study area.

The calculation of this index Iv requires the estimation of the three parameters and the weights $\alpha, \beta$ and $\gamma$.

\subsection{Estimate of the parameters of the TCR method}

\subsubsection{Transit time $T$}

Transit time $\mathrm{T}$ is the sum of the transit time (Ti) of each sub-layer crossing from the ground surface to the water table, it is calculated by:

$$
\mathrm{T}=\sum_{\mathrm{i}=1}^{\mathrm{n}} \mathrm{Ti} \quad \text { where } \mathrm{Ti}=\mathrm{hi} / \mathrm{Vi}
$$

$\mathrm{Vi}$ : average infiltration speed characterizing each type of rock crossed by the pollutant;

hi: thickness of each sub- layer constituting the unsaturated zone ;

$\mathrm{n}$ : the number of sub - layers which is always finite.

The parameter $(\mathrm{T})$ depends on several factors and the difficulty of its estimation lies in the selection of the infiltration speed considered, Vi.

In heterogeneous areas where the medium is composed of mixtures of different materials and textures, the estimation of filtration speed and degree of purification is very complicated. Indeed, the average filtration rate $(\mathrm{Vi})$, characterizing the different types of rocks representing the study area, was estimated based on previous studies [5], [7] and [8] and by determining the speed of filtration and the purification index of untreated mixtures in these studies.

If we consider two types of materials with a transit time $\mathrm{Ti}$ and filtration speed $\mathrm{Vi}$, where $\mathrm{i}=1,2$. The time $\mathrm{T}$ is the sum of the transit time of the two soils:

$$
\mathrm{T}=\alpha \mathrm{T}_{1}+(1-\alpha) \mathrm{T}_{2}
$$

were: $\alpha$ is the proportion of the material 1 and $(1-\alpha)$ the proportion of the material 2 .

The determination of the infiltration speed $\mathrm{V}$ is estimated by the relation (2):

$$
\mathbf{V}=\frac{\mathrm{h}}{\mathrm{T}}=\frac{\mathrm{V}_{1} \mathrm{~V}_{2}}{\alpha \mathrm{V}_{2}+(1-\alpha) \mathrm{V}_{1}}
$$

Where $\mathrm{h}$ is the thickness of the zone composed by the two materials. The infiltration speed of the mixture varies between the two velocities $V_{1}$ and $V_{2}$ and it takes the value $V_{1}$ for $\alpha=1$ and is equal to $V_{2}$ for $\alpha=0$ (Fig.2). 


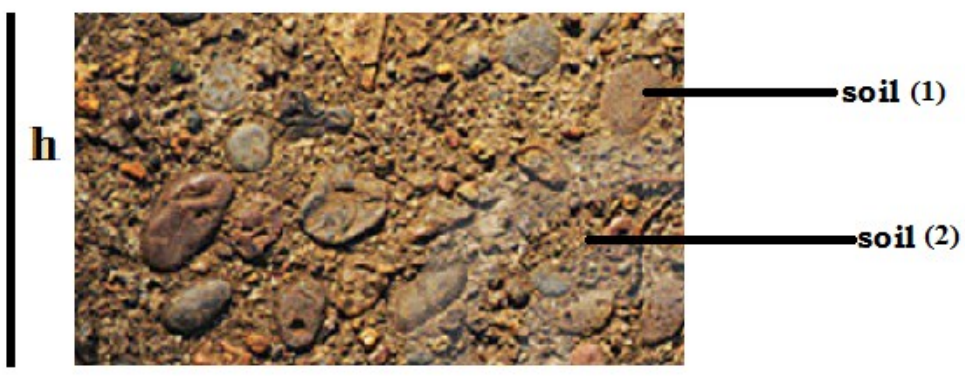

Figure 2: Example of an heterogeneous medium

The previous studies and the relation (2) allow us the estimate some heterogenic media given in Table 1.

\subsubsection{Purification degree $C^{\prime} \mathbf{p} / \mathbf{C p}$}

The $\mathrm{C}^{\prime} \mathrm{p} / \mathrm{Cp}$ ratio corresponds to the reduction of the concentration degree of polluted water reaching at the aquifer. It is approached with the purifying power Md of the cover layer [5]. Its calculation is made by considering the relation (3):

$$
C_{p}^{\prime} / C_{P}=\left\{\begin{array}{lll}
1-M_{d} & \text { si } M_{d}<1 & \text { case of partiel purification } \\
0 & \text { si } M_{d} \geq 1 & \text { case of totale purification }
\end{array}\right.
$$

$\mathrm{Md}$ is the purifying power; it depends on the thickness and nature of the layers crossedin unsaturated condition [7] et [9]. It is calculated along the vertical path by the relation (4):

$$
\mathrm{M}_{d}=\sum_{\mathrm{i}=1}^{\mathrm{n}} \mathrm{hi} * \mathrm{Ii}
$$

hi: thickness of each sub- layer constituting the unsaturated zone ;

Ii: Purifying Rehse index defined in terms of physical and hydrodynamic parameters for different types of materials in unsaturated conditions. It is related to the permeability and the retention capacity of the constituents of each material;

$\mathrm{n}$ : the number of sub - layers constituting the unsaturated zone.

\begin{tabular}{|c|c|c|}
\hline MATERIALS & FLTRATION SPEED (m/d) & PURIFICATION INDEX \\
\hline Clay & 0,003 & 0,5 \\
\hline loamy Clay & 0,010 & 0,5 \\
\hline clayey loam / loamy clay & 0,0175 & 0,5 \\
\hline Clayey loam & 0,025 & 0,5 \\
\hline fine loam & 0,16 & 0,4 \\
\hline Sandy Clay & 0,57 & 0,32 \\
\hline Sandy loam & 0,74 & 0,31 \\
\hline clayey fine sand & 1,1 & 0,246 \\
\hline clayey sand & 1,44 & 0,242 \\
\hline clayey coarse Sand & 1,5 & 0,241 \\
\hline loamy fine sand & 4 & 0,221 \\
\hline loamy sand & 4,32 & 0,22 \\
\hline loamy coarse sand & 4,77 & 0,216 \\
\hline fine sandstone & 5,4 & 0,2 \\
\hline fine sand & 8,23 & 0,17 \\
\hline Sandstone fine sand & 11,93 & 0,143 \\
\hline sandstone & 15,4 & 0,126 \\
\hline sandy sanstone & 16,48 & 0,123 \\
\hline sand and sandstone & 17,3 & 0,115 \\
\hline sandstone sand & 17,74 & 0,11 \\
\hline sand & 19,2 & 0,1 \\
\hline coarse sandstone & 21,6 & 0,09 \\
\hline coarse Sand & 27 & 0,07 \\
\hline Slightly Sandy Gravel & 480 & 0,03 \\
\hline
\end{tabular}

Table 1: Index of purification and filtration rate of different materials 


\subsubsection{Recharge degree $R^{\prime} / R$}

The recharge degree $R^{\prime} / R$ represents the degree of aquifer recharge and is therefore the transfer factor of pollutants to the water through the unsaturated zone. Potential contamination of a sheet is therefore linked to the degree of recharge [3]. However, this parameter is not easy to estimate; in this study it was assessed by the water balance.

\subsubsection{Sensitivity tests}

The determination of the weight coefficients $\alpha, \beta$ and $\gamma$ is made by sensitivity tests, followed by multiple linear regression analysis of the index Iv and of the three parameters $\left(1 / T, C^{\prime} p / C p\right.$ and $\left.R^{\prime} / R\right)$. This analysis is performed on control wells. These wells are chosen to reflect the important changes in the three parameters (transit time, purification degree and recharge degree). The fictive wells $\mathrm{N}^{\circ} 1111$ with $\mathrm{T}=1, \mathrm{C}^{\prime} \mathrm{p} / \mathrm{Cp}$ $=1$ and $\mathrm{R}^{\prime} / \mathrm{R}=1$ is taken as reference wells and used to classify all wells.

The principle of sensitivity tests consists in:

1) Classifying these wells relative to the reference wells (wells No. 1111: fictive wells with $T=1, C^{\prime} p / C p=1$ and $R^{\prime} / R=1$ ) to facilitate the ascending qualitative ranking of all wells;

2) Considering that standardized $\alpha, \beta$ and $\gamma$ weights vary in the bracket $[0-1]$ and $\alpha+\beta+\gamma=1$;

3) Removing the combinations whose qualitative classification is different from that performed;

4) Calculating Iv average for each combination with a pitch of 0.1 , with the same ascending qualitative ranking of control wells;

5) Applying multiple linear regression analysis of the values of the three parameters and Iv means to estimate the values of the weight coefficients $\alpha, \beta$ and $\gamma$ for each chosen year. For more details on sensitivity tests and their application method see: [4].

\subsection{Analysis of the TCR method parameters}

The spatio-temporal variation in rainfall and temperature causes a variation in the blade of infiltrated water, and consequently the recharge degree varies. The increase of the blade of infiltrated water causes a decrease in the thickness of the unsaturated zone and a variation in the horizons making up this area. This change in the lithology causes a change in the transit time. This is reflected by changes in the maps of the three parameters.

\subsection{Presentation of the study area}

III. Assessment of vulnerability by the TCR method in 2003 and 2005

The R'Mel aquifer is located in the North-West of Morocco; it is a part of the Bas-Loukoss Basin localized in the South of the city of Larache (Morocco). It extends over an area of approximately $240 \mathrm{~km}^{2}$. It is limited by the Atlantic Ocean to the West, Oued Loukossto the East and the marl outcrop Mio-Pliocene in the South. It is drained by the three rivers (Oueds): Sakh-Sokh, Smid El Ma and El Kihel (Fig. 3).

This area is classified in the field of sub-humid Mediterranean climate characterized by a hot and dry summer and a mild and humid winter. The annual average temperature varies between $11^{\circ} \mathrm{C}$ in winter and $25^{\circ} \mathrm{C}$ in the summer; the average annual rainfall is $700 \mathrm{~mm}$ distributed between October and April [10].

The results of the geophysical surveys and data extracted from the logs of boreholes have revealed two aquifer units consist mainly of dune sands and sandstones of Late Quaternary, and shelly sandstone PlioVillafranchien. The substratum of the R'Mel aquifer consists essentially of blue marl Mio- Pliocene [11].

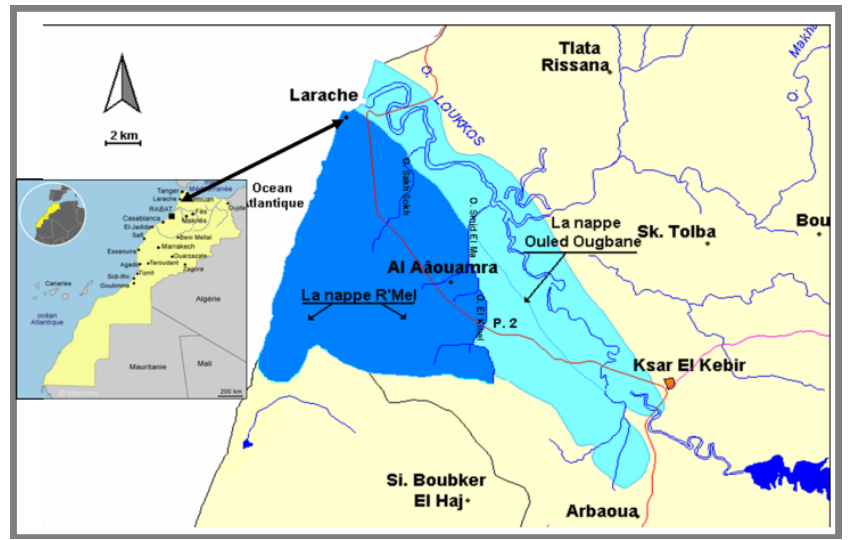

Figure 3: Location of the R'Mel aquifer (Larache, Morocco) 


\subsection{Mapping of the tree parameters of the TCR method}

\subsubsection{Assessment of recharge degree}

The recharge of the R'Mel aquifer occurs mainly through the effective infiltration of precipitations and irrigation water returns. However, the irrigation water return has not been taken into account in this portion of the study. Effective infiltration is determined by the water balance using climate data of Larache, Laouamra and M'rissa stations for the two years 2003 and 2005. It should be noted that surface runoff has been neglected due to the sandy nature of the soil and the low values of the slopes of the R'Mel plain. The interpolation of the values of the ratio of the effective infiltration estimated in each of the data points, for the three stations, on the potential rainfall for the two years 2003 and 2005 allowed us to obtain two different maps (Fig.4; Table 3).

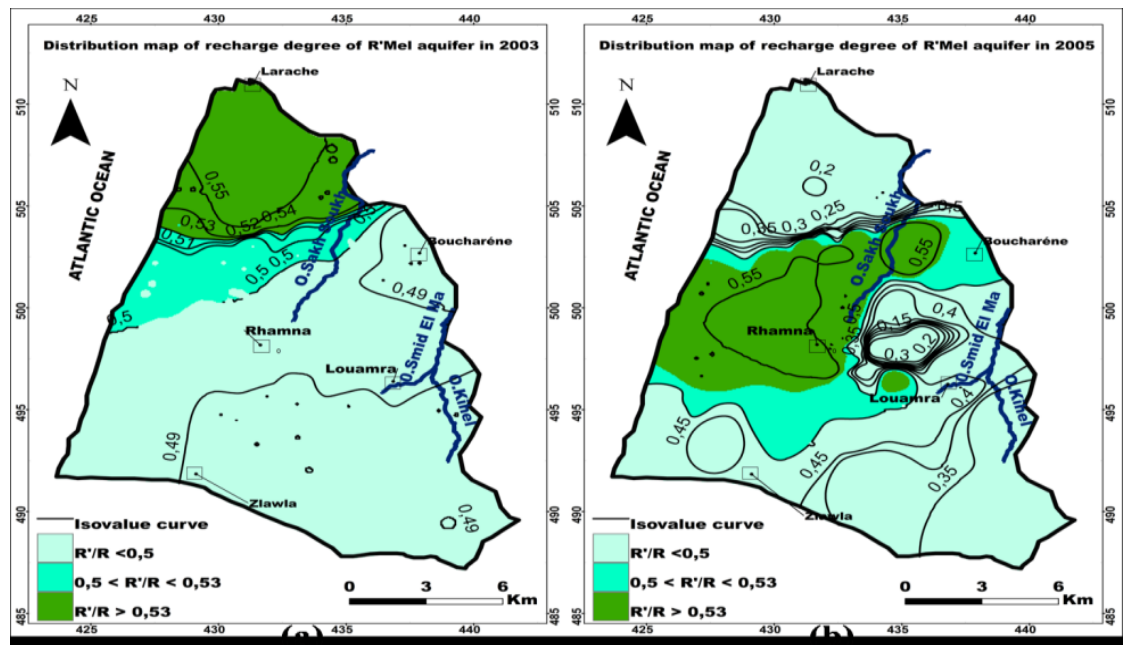

Figure 4: Maps of the recharge degree of $R^{\prime} M e l$ aquifer (a): in 2003; (b): in 2005

\subsubsection{Assessment of transit time and purification degree}

These two parameters were calculated by correlating data from profiles of wells drilled in the pedology studies [12], [13], [14], [15] and [16], wells and drilling logs carried out by the Department of Hydraulics and follow-up data of piezometers capturing the free R'Mel aquifer. These data are provided by the Loukkos Office of Agricultural Development (ORMVAL), Loukkos Water Basin Agency and the Department of Public Works. The interpolation of values calculated at each data point allowed us to have two maps, one for each year under consideration and for each parameter (Fig. 5; Fig.6 ; Table 3).
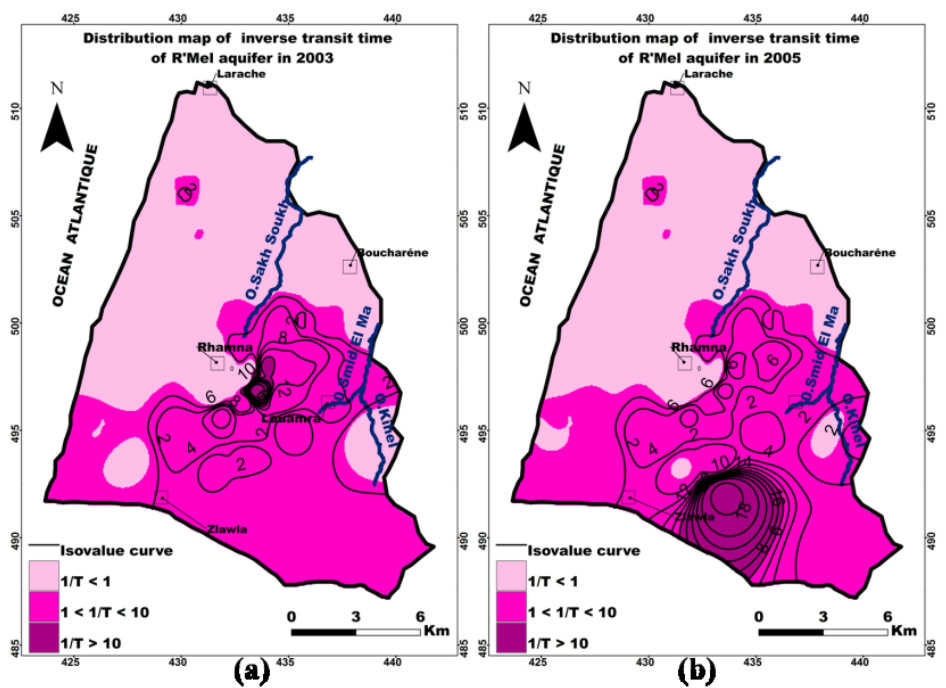

Figure 5: Maps of the inverse transit time of $R^{\prime} M e l$ aquifer (a): in 2003; (b): in 2005 

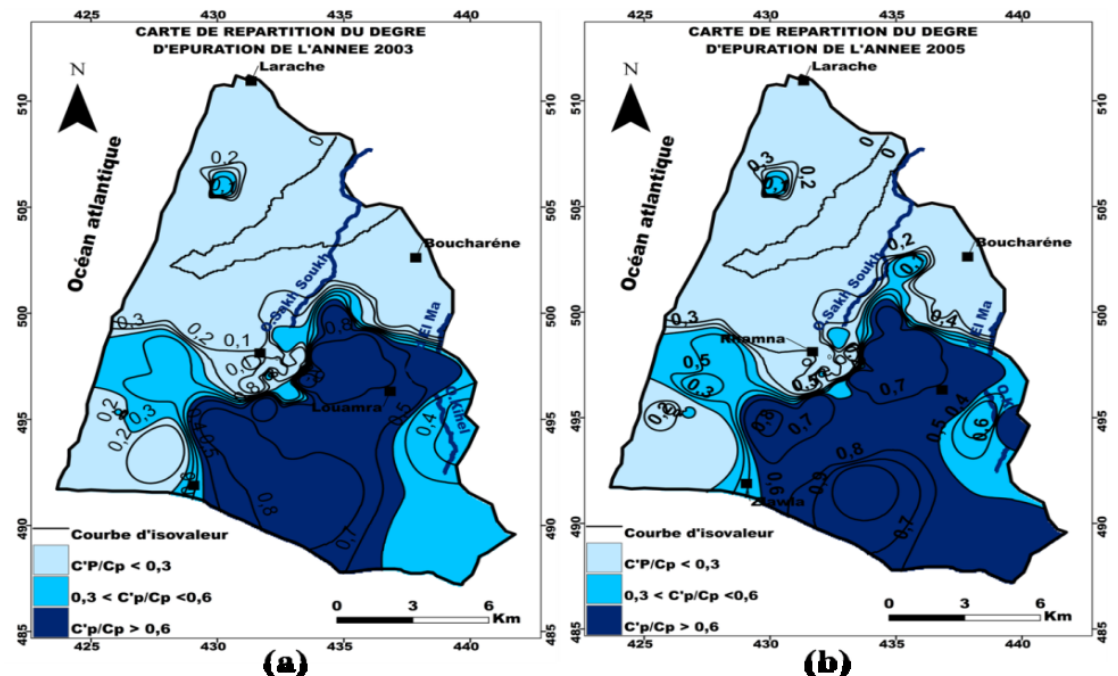

Figure 6: Maps of the purification degree of R'Mel aquifer (a): in 2003; (b): in 2005

\subsection{Assessments of the weight coefficients for the years 2003 and 2005}

The sensitivity tests were performed on 15 control wells representing significant changes in the three parameters T, C'p/Cp and R'/R for each rainfall years: 2003 and 2005 (Table 2). The best linear combination, according to the criteria of least squares, estimating the vulnerability index based on three parameters, gave the same values for the weight coefficients : $\alpha=2$ and $\beta=\gamma=1.5$. It is noted that the values of these weight coefficients differs from those obtained for the Gharb aquifer [4].

Table 2: Data and classification of control wells in 2003 and 2005

\begin{tabular}{|c|c|c|c|c|c|c|c|c|c|c|c|}
\hline Well $\mathbf{N}^{\circ}$ & T 2003 & $\begin{array}{c}1 / T \\
2003\end{array}$ & $\begin{array}{c}C^{\prime} p / \mathbf{p} p \\
2003\end{array}$ & $\begin{array}{c}\mathbf{R}^{\prime} / \mathbf{R} \\
2003\end{array}$ & $\mathbf{I}_{\mathbf{V}}$ (Medium) & $\mathbf{N}^{\circ}$ Well & T 2005 & $\begin{array}{c}1 / \mathbf{T} \\
2005\end{array}$ & $\begin{array}{c}C^{\prime} p / C p \\
2005\end{array}$ & $\begin{array}{l}\mathbf{R}^{\prime} / \mathbf{R} \\
2005\end{array}$ & $\mathbf{I}_{\mathbf{V} \text { (Medium) }}$ \\
\hline $1687 / 3$ & 379,90 & 0,0026 & 0 & 0,49 & 0,15 & $1396 / 3$ & 7,13 & 0,1402 & 0 & 0,22 & 0,12 \\
\hline $1396 / 3$ & 7,00 & 0,1428 & 0 & 0,55 & 0,22 & $1687 / 3$ & 379,92 & 0,0026 & 0 & 0,53 & 0,16 \\
\hline $1535 / 3$ & 3,12 & 0,3208 & 0 & 0,53 & 0,29 & $1535 / 3$ & 3,13 & 0,3196 & 0 & 0,34 & 0,23 \\
\hline $1534 / 3$ & 2,39 & 0,4184 & 0 & 0,55 & 0,33 & $1534 / 3$ & 2,43 & 0,4119 & 0 & 0,24 & 0,23 \\
\hline $1685 / 3$ & 1,84 & 0,5431 & 0 & 0,48 & 0,36 & $1685 / 3$ & 1,85 & 0,5401 & 0 & 0,51 & 0,37 \\
\hline $1414 / 3$ & 1,66 & 0,6018 & 0,11 & 0,50 & 0,42 & $1661 / 3$ & 1,18 & 0,8456 & 0 & 0,20 & 0,39 \\
\hline $1661 / 3$ & 1,14 & 0,8801 & 0,00 & 0,55 & 0,51 & $1414 / 3$ & 1,72 & 0,5806 & 0,03 & 0,55 & 0,40 \\
\hline $1365 / 3$ & 1,29 & 0,7781 & 0,47 & 0,50 & 0,60 & $1365 / 3$ & 1,44 & 0,6950 & 0,42 & 0,56 & 0,57 \\
\hline $1111 / 3$ & 1 & 1 & 1 & 1 & 1 & $2643 / 3$ & 1,03 & 0,9689 & 0,68 & 0,51 & 0,74 \\
\hline $342 / 3$ & 0,56 & 1,7948 & 0,47 & 0,55 & 1,01 & $342 / 3$ & 0,56 & 1,7798 & 0,47 & 0,22 & 0,90 \\
\hline $2643 / 3$ & 0,55 & 1,8066 & 0,81 & 0,48 & 1,09 & $1111 / 3$ & 1 & 1 & 1 & 1 & 1 \\
\hline $1413 / 3$ & 0,41 & 2,4307 & 0,36 & 0,50 & 1,20 & $1413 / 3$ & 0,44 & 2,2942 & 0,32 & 0,55 & 1,15 \\
\hline $1580 / 3$ & 0,35 & 2,8504 & 0,86 & 0,48 & 1,51 & $2735 / 3$ & 0,28 & 3,6346 & 0,60 & 0,31 & 1,68 \\
\hline $2735 / 3$ & 0,29 & 3,4704 & 0,58 & 0,49 & 1,67 & $1581 / 3$ & 0,19 & 5,3000 & 0,81 & 0,52 & 2,46 \\
\hline $1581 / 3$ & 0,18 & 5,6118 & 0,82 & 0,49 & 2,61 & $1401 / 3$ & 0,16 & 6,0963 & 0,77 & 0,51 & 2,75 \\
\hline $1401 / 3$ & 0,12 & 8,2300 & 0,83 & 0,48 & 3,58 & $1580 / 3$ & 0,05 & 20,2579 & 0,93 & 0,36 & 8,23 \\
\hline
\end{tabular}

\section{Results And Discussion}

The application of the TCR method for estimating and mapping the vulnerability of the R'Mel aquifer allowed us to get three thematic maps and one vulnerability map for each rainfall year (Fig. 7). The index values of the Iv calculated were divided into four classes of vulnerability. The choice of these brackets was based on an analysis of transit time and the degree of purification of all wells and their contrast with the geological and hydrogeological data for the study area.

The comparison of the two vulnerability maps obtained for the two years 2003 and 2005 was made by a surface analysis to spatially locate areas of similarity and dissimilarity. The analysis of the results showed a concordance of $92 \%$ of the surface of the study area. This similarity of results (identical index) concerns in particular classes of high and extreme vulnerability. On the other hand, the Kappa test [17] showed that these two maps have a strong agreement of about 0.78 and that the agreement was not due to sheer coincidence remains average $(\mathrm{K}=0,33)$.

Thematic maps show variations of $14 \%$ for transit time, $16 \%$ for the degree of purification and $51 \%$ for the degree of recharging of the total surface of the study area (Table 2). However, final vulnerability maps differ only by $8 \%$. This shows that the TCR method reduces the effect of spatio-temporal variations of the three related parameters used $\left(1 / \mathrm{T}, \mathrm{C}^{\prime} \mathrm{p} / \mathrm{Cp}\right.$ and $\left.\mathrm{R}^{\prime} / \mathrm{R}\right)$. It greatly minimizes the effect of the recharge, taking into account the rate groundwater recharge. In addition to the weights coefficients, the charge degree and the purification degree are lower $(\beta=\gamma=1,5)$ than that of the transit time $(\alpha=2)$. 
Both vulnerability maps obtained are slightly different, while thematic maps of the three parameters have significant variations. Moreover, the weight coefficients of the TCR method, determined by sensitivity tests, are the same for the two years. However, for the two years the weight coefficients are the same and sensitivity tests performed for the Gharb aquifer gave different results compared to our study area $(\alpha=\beta=2$ and $\gamma=1)[4]$.

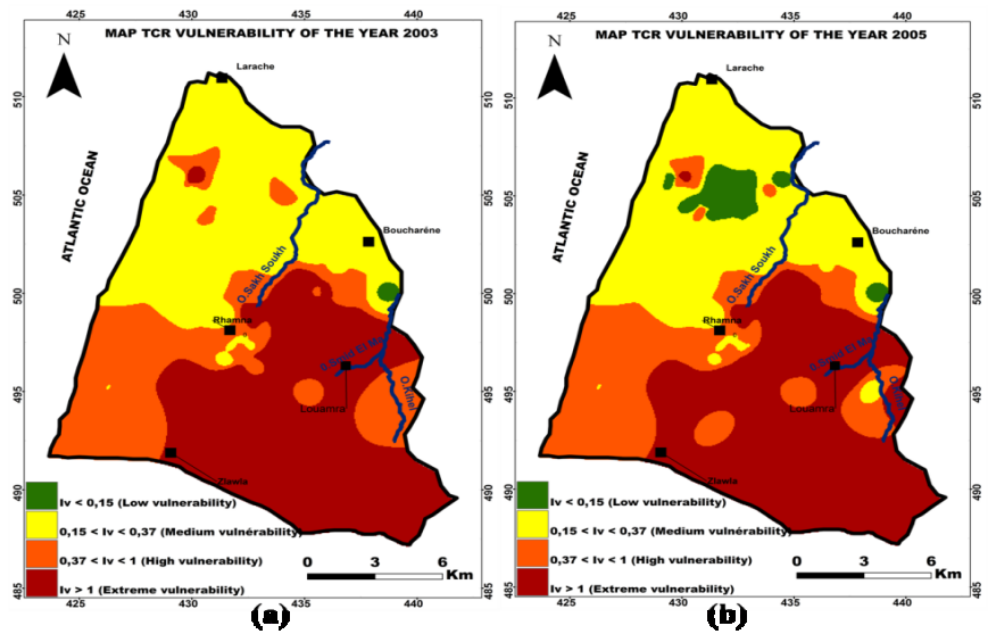

Figure 7: Maps of intrinsic vulnerability of the aquifer R'Mel by the TCR method (a): in 2003(b): in 2005

Table 3: Variation of the classes of the three TCR parameters and the percentage of areas occupied by the different classes of the aquifer $R^{\prime}$ Mel for the two years.

\begin{tabular}{|c|c|c|}
\hline Value of the parameter & \multicolumn{2}{|c|}{ Area occupied by \% } \\
\cline { 2 - 3 } $1 / \mathbf{T}$ & 2003 & 2005 \\
\hline $1 / \mathbf{T}<1$ & $47 \%$ & $44 \%$ \\
$1<1 / \mathbf{T}<10$ & $52 \%$ & $49 \%$ \\
$1 / \mathbf{T}>10$ & $1 \%$ & $7 \%$ \\
\hline $\begin{array}{c}\text { Value of the parameter } \\
\text { C'p/Cp }\end{array}$ & \multicolumn{2}{|c|}{ Area occupied by \% } \\
\cline { 2 - 3 } & 2003 & 2005 \\
\hline $\mathbf{C}^{\prime} \mathbf{p} / \mathbf{C} \mathbf{p}<\mathbf{0 , 3}$ & $49 \%$ & $49 \%$ \\
$0,3<\mathbf{C}^{\prime} \mathbf{p} / \mathbf{C p}<\mathbf{0 , 6}$ & $22 \%$ & $15 \%$ \\
$0,6<\mathbf{C}^{\prime} \mathbf{p} / \mathbf{C p}<1$ & $29 \%$ & $36 \%$ \\
\hline Value of the parameter & \multicolumn{2}{|c|}{ Area occupied by \% } \\
\cline { 2 - 3 } $\mathbf{R}^{\prime} / \mathbf{R}$ & 2003 & 2005 \\
\hline $\mathbf{R}^{\prime} / \mathbf{R}<\mathbf{0 , 5}$ & $74 \%$ & $43 \%$ \\
\hline $0,5<\mathbf{R}^{\prime} / \mathbf{R}<\mathbf{0 , 5 3}$ & $10 \%$ & $14 \%$ \\
\hline $\mathbf{R}^{\prime} / \mathbf{R}>\mathbf{0 , 5 3}$ & $16 \%$ & $43 \%$ \\
\hline
\end{tabular}

\section{Conclusion}

In this work, we have shown, through the application of the TCR method to the R'Mel aquifer for two different rainfall years that vulnerability is dynamic: spatial distribution of the degrees of vulnerability varies significantly from one year to the other. However, this spatial and temporal variability is clearly visible at the level of the three parameters considered: transit time, recharge degree and purification degree. While the weights estimated by sensitivity tests are similar for the two selected years, they differ from those determined for the Gharb aquifer. Therefore, the TCR method attenuates the effects of spatial and temporal variations in rainfall on the vulnerability index because it uses the ratio of the parameters $\left(R^{\prime} / R, C^{\prime} p / C p\right.$ and $\left.1 / T\right)$. To consolidate these results, further studies are necessary, taking into account rainfall data with larger variations.

\section{Acknowledgements}

This work was done in collaboration with the Regional Office of Agricultural Development Loukkos (ORMVAL) Ksar El Kebir, Morocco, following an agreement between the Faculty of Sciences and Techniques of Tangier and The ORMVAL. 


\section{References}

[1]. M Albinet, and J.Margat, Cartographie de la vulnérabilité à la pollution des nappes d'eau souterraines. Bull. BRGM, $2^{\mathrm{e}}$ série, section III, 4, 1970, 3-22, Orléans.

[2]. J Margat, and M.F.Suais-Parascandola, Mapping the vulnerability of groundwater to pollution, some lessons from experience in France.In: W. Van Duijvenbooden and H.G. VanWaegeningh (Editors), Vulnerability of soil and groundwater to pollutants, The Hague, 1987, pp. 433-436.

[3]. M. Amharref, J. Mania, and B. Haddouchi, Adaptation of an evaluation vulnerability method to groundwater pollution.Proceeding of salt water intrusion in coastal aquifer: Monitoring, Modeling, and Management,Essaouira (Maroc), 23-25 avril, 2001, pp.1-10.

[4]. M Amharref, S.Assine, A. Bernoussi, and B. Haddouchi, Cartographie de la vulnérabilité à la pollution des eaux souterraines: application à la plaine du Gharb (Maroc). Revue science de l'eau 20 (2), 2007, 185-199.

[5]. A Bernoussi, and M.Amharref, Étalabilité vulnérabilité. Ann. Univ. Craiova Ser. Math. Comp. Sci.,30,2003, 53-62.

[6]. M.Amharref, S.Aassine and A. Bernoussi, Cartographie de la vulnérabilité des eaux souterraines : application au cas de la plaine du Gharb. Proc. Congrès international de mathématiques appliquées JANO7,2002, Tanger 17-19 avril. CD-Rom édité par la Faculté des Sciences et Techniques, Tanger, Maroc.

[7]. W Rehse, Elimination und abbaue von organischefremdastoffen, pathogenenkeimen und vireninlockergestein.Z. Dt. Geol. Ges., 1977, 128, 319-329.

[8]. L. Maxe and P.O. Johansson, Assessing groundwater vulnerability using travel time and specific surface area indicators.hydol. j., 6, 1998, 441-449.

[9]. A. Lallemend-Barres and J.C. Roux, Guide méthodologique d'établissement des périmètres de protection des captages d'eau souterraine destinée à la consommation humaine. BRGM, Manuels et Méthode, 1989, 19, 1-224.

[10]. ORMVAL (Office Régional de Mise en Valeur Agricole de Loukkos). 2004. Bulletin de l'office régional de mise en valeur agricole de loukkos, Altopress, Tanger.

[11]. Messaoud, M. (1963). Etude hydrogéologique du bassin du bas Loukoss. Rapp. inéd. MTPC/DH/DRE, 111 pp.

[12]. ONI (Office Nationale des Irrigations). 1963. Aménagement du bassin versant de l'oued Loukkos : étude des sols du plateau du R'Mel à l'échelle du 1/20.000.

[13]. SICORES (Société Internationale de Coopération pour Réalisations Economiques et Sociales) 1971. Etude pédologique et de reconnaissance des sols au $1 / 50.000$.

[14]. ORMVAL (Office Régional de Mise en Valeur Agricole de Loukkos). 1976. L'étude pédologique de R'Mel II zone thé au $1 / 20.000$.

[15]. ORMVAL (Office Régional de Mise en Valeur Agricole de Loukkos). 1986. L'étude pédologique de la zone Haraska secteur R'Mel au 1/20.000.

[16]. ORMVAL (Office Régional de Mise en Valeur Agricole de Loukkos). 1994. Etude pédologique au 1/5.000éme du domaine Bargha de la Sogéta.

[17]. P. Bernard, Théorie et application du coefficient de Kappa. Thèse de doctorat, Université Laval, ISBN: 0-315-85514-2, 1993. 